\title{
GPs' Interactional Styles in Consultations with Dutch and Ethnic Minority Patients
}

\author{
Barbara C. Schouten - Ludwien Meeuwesen • \\ Hans A. M. Harmsen
}

Published online: 23 March 2008

(C) The Author(s) 2008

\begin{abstract}
The aim of this study was to examine interactional styles of general practitioners (GPs) in consultations with Dutch patients as compared to ethnic minority patients, from the perspective of level of mutual understanding between patient and GP. Data of 103 transcripts of videoregistered medical interviews were analyzed to assess GPs' communication styles in terms of involvement, detachment, shared decision-making and patient-centeredness. Surveys were used to collect data on patients' characteristics and mutual understanding. Results show that overall, GPs communicate less adequately with ethnic minority patients than with Dutch patients; they involve them less in decisionmaking and check their understanding of what has been discussed less often. Intercultural consultations are thus markedly distinguishable from intracultural consultations by a lack of adequate communicative behavior by GPs. As every patient has a moral and legal right to make informed decisions, it is concluded that GPs should check more often whether their ethnic minority patients have understood what has been said during the medical consultation.
\end{abstract}

B. C. Schouten $(\bowtie)$

Department of Communication, The Amsterdam School

of Communications Research (ASCoR), University

of Amsterdam, Kloveniersburgwal 48, Amsterdam 1012 CX,

The Netherlands

e-mail: b.c.schouten@uva.nl

L. Meeuwesen

Interdisciplinary Social Science Department, Research Institute for Psychology and Health, Utrecht University, Utrecht,

The Netherlands

H. A. M. Harmsen

Department of Health Policy and Management, Erasmus MC,

University Medical Centre Rotterdam, Rotterdam,

The Netherlands
Keywords Doctor-patient communication . Communication styles - Intercultural communication . Ethnicity $\cdot$ Shared decision-making

\section{Introduction}

Background

Good doctor-patient communication is positively related to patient understanding, satisfaction and compliance with recommended treatment [1]. Doctors are therefore expected to demonstrate adequate communicative skills. Adequate communication between general practitioners (GPs) and patients often seems difficult to achieve though, especially with patients from ethnic minority groups. Research has shown that there is less socio-emotional exchange in interactions between white doctors and ethnic minority patients, and comments of patients from ethnic minority groups are ignored more often than comments of white patients [2-5]. The particular lack of socio-emotional expressiveness makes establishing a relationship of mutual trust with shared medical decision-making and mutual understanding more difficult to attain, resulting in diminished patient compliance and satisfaction [6-9].

To improve intercultural doctor-patient communication, more knowledge about the nature of the communicative difficulties is needed. Unfortunately, with some notable exceptions (e.g. [10]) the few studies on this topic have relied predominantly on analyses in which doctor-patient communication has been coded separately from contextthat is, most studies are based on frequency of doctors' and patients' verbal utterances, without much attention given to non-verbal and paralingual communicative aspects such as tone of voice, eye contact, sequential chain of interaction 
and the broader context. Crucial aspects of the communication process have thus been largely neglected. To address this gap, the present study will make use of a recently developed method, based on an interactional perspective, and takes into account context ([11]; see "Methods" section). The overall aim of this study is to investigate whether there are differences in GPs' use of interactional styles between consultations with Dutch and ethnic minority patients. Specifically, it is assumed that GPs will interact less adequately with the latter group than with Dutch patients $[2,3]$. Another assumption is that more adequate doctor-patient interaction will be positively related to enhanced mutual understanding between them, as previous research has clearly established a positive link between good doctor-patient communication and subsequent patient understanding of what has been discussed during the medical consultation [1].

\section{Theoretical Framework}

Several developments in the last 20 years have stimulated a paradigm shift away from medical paternalism toward more patient autonomy. The growing assertiveness of many patients, resulting from higher levels of education as well as from the ongoing individualism of our period, and scientific and technological processes that have increased medicine's potentiality to encroach deeply on human life, are two of the most important factors in this respect [12]. A core concept illustrating this paradigm shift is the notion of patient-centeredness, which is the ideal of an egalitarian doctor-patient relationship in which doctors and patients share responsibility for the interaction and its outcomes, thereby taking the perspective of the patient's need for cure and care [13-16].

In light of these developments, the dependent and unequal position of patients, in particular those belonging to ethnic minority groups, has increasingly been criticized, and various Western countries have now adopted regulations to make patients equal parties to doctors under the law. The doctrine of informed consent-the right of the patient to be able to make an informed decision concerning a proposed treatment-is probably the most well-known legal regulation. In line with this paradigm shift, much empirical research has been conducted to test the extent to which concepts like patient-centeredness and informed consent actually take place during medical encounters (e.g. [17]). Within the research domain of (intercultural) health communication, the approach most often used has been the coding and counting of speech acts in mutually exclusive categories, by means of coding systems derived from (medical) psychological theory.

One obvious limitation of such an approach is that is does not generate any insight into the interactional dynamics of conversations. To illustrate, the sentence "I understand how you feel" can mean several things, depending on tone of voice, accompanying non-verbal behaviors, sequencing of sentences and so on. For instance, a doctor uttering this sentence while looking at the clock to see what time it is and subsequently finishing the consultation by saying goodbye and walking toward the door is communicating something entirely different than a doctor uttering the same sentence while making eye contact with the patient and subsequently asking the patient how he can help him alleviate his worries. In traditional coding systems this sentence would have been scored the same, but by taking an interactional perspective we are able to distinguish the mere rapport words or trained empathy of the first doctor from the rapport work and genuine empathy of the second doctor.

As only scarce research attention has been given to interactional styles as opposed to verbal communicative utterances, there is a lack of valid and reliable methods to assess doctors' interactional styles during medical consultations. Recently, Roberts and Sarangi [11] developed a method by which the interactional involvement of health care practitioners with their patients can be assessed. Their method is theoretically grounded in conversation analysis and ethnography, and draws further on the sociolinguistic work of researchers like Gumperz [18], Tannen [19], and Goffmann [20]. In essence, their approach, which they refer to as interactional sociolinguistics, looks at "how individuals differ in the ways in which they interact with and understand each other" ([21], p. 194). To study these interactional styles, naturally occurring examples of talk are used. The development of their method is based on observations of medical students' consultations [21]. The essence of this method is a strong focus on the context of the interaction. Roberts et al. [11] sharply distinguish between negative and positive modes of interacting, which they refer to as involvement styles versus detachment styles. The valence of the interaction is explicitly taken into account as well. In that sense, their method enables describing differences in interactional styles in medical consultations and assessing to what extent the medical consultation is or is not patient-centered.

\section{Methods}

\section{Participants and Data Collection}

Data of the Rotterdam Intercultural Communication in Medical Settings (RICIM) project were used, in which patients of 38 general practices with a multi-ethnic population participated [22]. Informed consent was obtained for all study participants. Written transcripts according to rules of Conversation Analysis [23] were made of a selection of 
these (videotaped) consultations. The selection was based on the lowest and highest quartiles of level of mutual understanding between doctor and patient (see "Measures" section). This resulted in a dataset of 103 patients (56 patients belonging to one of the major ethnic minority groups in the Netherlands-Turkish, Moroccan, Surinamese, Antillean, Cape Verdian-and 47 Dutch patients) and 29 GPs (22 male and 7 females). Most GPs were between 40 and 55 years old and had a minimum professional work experience of 5 years.

Scoring was based on videotapes and verbatim transcripts, which enables taking context and tone of voice as much as possible into account. The unit of analysis was at topic level, but to ensure all utterances were scored properly the entire consultation was always taken into account. Only utterances that could fit into one of the categories as identified by Roberts and Sarangi [11] were scored. Other utterances were considered "neutral" and were not taken into account. All 103 consultations were scored by a research assistant, who was experienced in coding doctorpatient communicative utterances and trained to score using the Roberts and Sarangi method. Ten consultations were randomly selected and rated by a second coder (first author) to establish interrater reliability, which proved to be satisfactory $(0.66$ for retractive behavior and 0.74 for stimulating behavior).

\section{Measures}

The following patient variables were included.

\section{Ethnic Background}

Patients were categorized into a Dutch or an ethnic minority group, based on their own and their parents' country of birth [24].

\section{Language Proficiency}

This was based on patients' self-report (good, moderate, and poor), which was highly comparable with interviewers' and GP's assessments (Spearman's $\rho>.72$ ).

\section{Other Socio-demographics}

Age, gender, religiosity (religious versus not-religious) and educational level (low: primary school; intermediate: lower/intermediate vocational education or lower general secondary education; high: general secondary education or higher $^{1}$ )

\footnotetext{
${ }^{1}$ Categories based on the Dutch educational system.
}

\section{GPs' Verbal Behavior}

Roberts and Sarangi [11] make a distinction between several stimulating and retractive interactional styles, which corresponds with the above-mentioned difference between involvement styles and detachment styles. Stimulating interactional styles refer to an empathic and attentive mode of interacting, by which a joint problem-solving framework with the patient can be built and active involvement between both parties is achieved. On the other hand, retractive interactional styles refer to a mode of interaction by which distance is created between doctor and patient, for instance by rushing through the medical consultation. To illustrate, two fragments are shown in Appendix A, one of a stimulating interactional style, one of a retractive interaction style.

Fragment 1 shows how doctor and patient are having a dialogue by overlapping each other and attentively responding to what has been said. In addition, the doctor gives a contextualizing cue by saying: "I think that you have more things, haven't you?" (line 9), making it clear to the patient where they are going. In doing so, the doctor is communicating in a patient-centered way, because he involves the patient in what is happening during the consultation. This cue also functions as a face-saving device, by giving the patient space to say whatever she wants.

In Fragment 2 the doctor does not acknowledge the patient's requests or feelings at all. The patient asks the doctor for information about smoking cessation pills, but the doctor does not take the time to respond to the patient's question. Instead, he rushes through the consultation by making it both verbally and non-verbally clear that the patient's question should be postponed until another consultation.

For purposes of this study, the following stimulating categories were used:

S1: Attentive responding. The GP follows the patient's storyline, picks up themes and makes adequate inferences from the narrative. The GP gives positive commentary to the patient's narrative and shows compassion.

S2: Joint problem-solving. The GP involves the patient in the decision-making process and checks his own understanding and the patient's.

S3: Contextualizing and face work. The GP clearly outlines the content of the consultation, and what will happen next. The GP is clear about his expectations and the information he needs from the patient, and takes into account feelings of embarassment the patient may have.

The following retractive categories were used:

R1: Inattentive responding. The GP does not react to the patient's remarks, makes embarrassing comments and does not acknowledge the patient's feelings. 
R2: Schema-driven progression. The GP drives through the medical agenda and makes rapid topic shifts. The conversation is driven by motives of swiftness and efficiency.

R3: Storage failure. The GP gathers information the patient has already mentioned implicitly or explicitly.

R4: Insensitivity to patient's level of understanding. The GP does not take into account the level of understanding of the patient, uses technical language and assumes that the patient knows which symptoms go with which diseases.

\section{Mutual Understanding}

This was assessed with the Mutual Understanding Scale (MUS), developed and validated by a multi-ethnic and multidisciplinary expert panel using nominal group technique [25]. Scores varied between -1 (very low) and +1 (very high). This resulted in a dataset of 45 consultations with poor mutual understanding (scores were between -1.0 and -0.4 for 18 Dutch and 27 ethnic minority patients) and 58 consultations with good mutual understanding (scores between +0.55 and +1 for 29 Dutch and 29 ethnic minority patients).

\section{Data Analysis}

Data were analyzed with SPSS 14.0. Frequencies of the interactional styles were assessed. $T$-tests were used to study differences in styles between consultations with Dutch and ethnic minority patients. Links between interactional styles and other patient variables were assessed by $t$-tests and correlation analysis. $T$-tests were run to assess differences in GPs' communicative behavior between consultations low and high in mutual understanding. In addition, to illustrate some of our main findings the analyses of two excerpts from transcripts are presented, supplemented by analytical comments.

\section{Results}

Sample

The ethnic minority group was younger, more religious and had poorer language proficiency in Dutch (Table 1). The two groups had about the same educational level.

Doctors' Interactional Styles

Mean number of stimulating utterances per consultation was significantly higher than mean number of retractive utterances $(M=10.5$ vs. $M=4.3 ; t(-8.7), p=.000)$.
Table 1 Patient sample

\begin{tabular}{llll}
\hline Patients' characteristics & $\begin{array}{l}\text { Total } \\
(n=103)\end{array}$ & $\begin{array}{l}\text { Dutch group } \\
(n=47)\end{array}$ & $\begin{array}{l}\text { Non-Western } \\
\text { group }(n=56)\end{array}$ \\
\hline $\begin{array}{l}\text { Sex (\%) } \\
\text { Men }\end{array}$ & 46.5 & 46.3 & 46.8 \\
Women & 53.5 & 53.7 & 53.2 \\
Age & & & \\
Mean (year) & 43.1 & 49.5 & 35.6 \\
& $(\mathrm{sd}=17.4)$ & $(\mathrm{sd}=16.8)$ & $(\mathrm{sd}=15.2)^{*}$ \\
Education (\%) & & & \\
Low & 39.2 & 38.2 & 40.5 \\
Intermediate & 35.0 & 30.9 & 40.5 \\
High & 25.8 & 30.9 & 19.0 \\
Religiously active (\%) & & & \\
Yes & 46.1 & 27.3 & $68.1 *$ \\
No & 53.9 & 72.7 & 31.9 \\
Language proficiency $(\%)$ & & \\
Poor/moderate & 32.0 & 4.8 & $52.7 *$ \\
Good & 68.0 & 95.2 & 47.3 \\
\hline
\end{tabular}

$* p<.001$

GPs showed "attentive responding" most often. With respect to retractive utterances, "inattentive responding" occurred the most (Table 2).

Ethnic minority patients heard slightly fewer stimulating utterances overall from their GP than Dutch patients $(t(1.5) ; p<.10)$. There was in particular significantly less "joint problem-solving" $(t(1.9) ; p<.05)$. In general, GPs behaved retractively to the same degree for both groups. The only difference was that consultations with Dutch patients were slightly more schema-driven than consultations with ethnic minority patients.

Table 2 mean scores on stimulating and retractive utterances for Dutch and non-Western patients

\begin{tabular}{|c|c|c|c|}
\hline \multirow[t]{2}{*}{ Category } & \multicolumn{3}{|l|}{ Mean (sd) } \\
\hline & $\begin{array}{l}\text { Total group } \\
(n=103)\end{array}$ & $\begin{array}{l}\text { Dutch } \\
(n=47)\end{array}$ & $\begin{array}{l}\text { non-Western } \\
(n=56)\end{array}$ \\
\hline S1attentive responding & $4.3(3.6)$ & $4.7(3.9)$ & $4.0(3.2)$ \\
\hline S2 joint problem solving & $3.3(2.4)$ & $3.7(2.5)$ & $2.8(2.2)^{* *}$ \\
\hline $\begin{array}{l}\text { S3 contextualizing and face } \\
\text { work }\end{array}$ & $3.0(3.0)$ & $3.2(3.0)$ & $2.8(3.0)$ \\
\hline Total stimulating & $10.5(6.7)$ & $11.6(6.6)$ & $9.7(6.7)^{*}$ \\
\hline $\mathrm{R} 1$ inattentive responding & $2.2(2.3)$ & $2.3(2.3)$ & $2.1(2.3)$ \\
\hline $\begin{array}{l}\mathrm{R} 2 \text { schema driven } \\
\text { progression }\end{array}$ & $1.8(1.9)$ & $2.1(2.1)$ & $1.5(1.7)^{*}$ \\
\hline R3 storage failure & $0.1(0.4)$ & $0.2(0.4)$ & $0.1(0.4)$ \\
\hline $\begin{array}{l}\text { R4 insensitivity to patient's } \\
\text { level of understanding }\end{array}$ & $0.2(0.5)$ & $0.2(0.6)$ & $0.2(0.5)$ \\
\hline Total retractive & $4.3(3.5)$ & $4.7(3.6)$ & $3.9(3.4)$ \\
\hline
\end{tabular}

$* p<.10 ; * * p<.05$ (one-tailed) 
Patient characteristics related to GPs' interactional styles were religiosity, age and sex. Religious patients heard fewer stimulating utterances than non-religious patients $(M=9.1$ vs. $M=11.9 ; t(-2.1), p<.05)$ and received less "attentive responding" (resp. $M=3.6$ and $M=5.0 ; t(-2.0), p<.05)$. When comparing frequencies between religious and non-religious ethnic minority patients no differences emerged, indicating that religion did have an independent influence on GPs' stimulating behavior. Being older was related to more retractive behavior $(\mathrm{r}=.35 ; p<.01)$, especially to "inattentive responding" $(r=0.21 ; p<.05)$ and "schema-driven progression" $(r=.37 ; p<.01)$. Male patients heard more utterances concerning "schema-driven progression" than female patients (resp. $M=2.3$ and $M=1.2 ; t(3.2)$; $p<.01$ ), while there was a trend for female patients to hear more utterances concerning "insensitivity to patient's level of understanding" than male patients (resp. $M=0.3$ and $M=0.1 ; t(-1.9), p=.07)$. No significant links emerged between educational level or language proficiency and GPs' interactional styles.

\section{Relations with Mutual Understanding}

Contrary to expectations, no differences emerged on GPs' stimulating behavior when comparing consultations low and high in mutual understanding. However, consultations low in mutual understanding were more retractive (mainly "inattentive responding" and "schema-driven progression") than consultations high in mutual understanding, which was expected $(t(2.1) ; p<.05)$.

Separate analyses for Dutch and ethnic minority patients revealed that no differences on stimulating behavior occurred among Dutch patients. However, there was more retractive behavior in consultations low in mutual understanding, particularly more "inattentive responding" and "schema-driven progression", than in high mutual understanding consultations ( $t(2.0), p=.05)$ (Fig. 1a). For the ethnic minority group, no differences in GPs' stimulating behavior or retractive behavior between consultations high and low in mutual understanding emerged (Fig. 1b).

\section{Joint Problem-Solving in Medical Encounters with Ethnic Minority Patients}

Two excerpts of transcripts are shown in Appendix B to illustrate GPs' communication regarding shared decisionmaking. The first example concerns a 28 -year-old male patient from Surinamese-Hindu background suffering from stomachaches, with low mutual understanding between patient and GP. The transcript starts after the physical examination. As shown, this portion of the consultation has received two codes: one of "schema-driven progression"
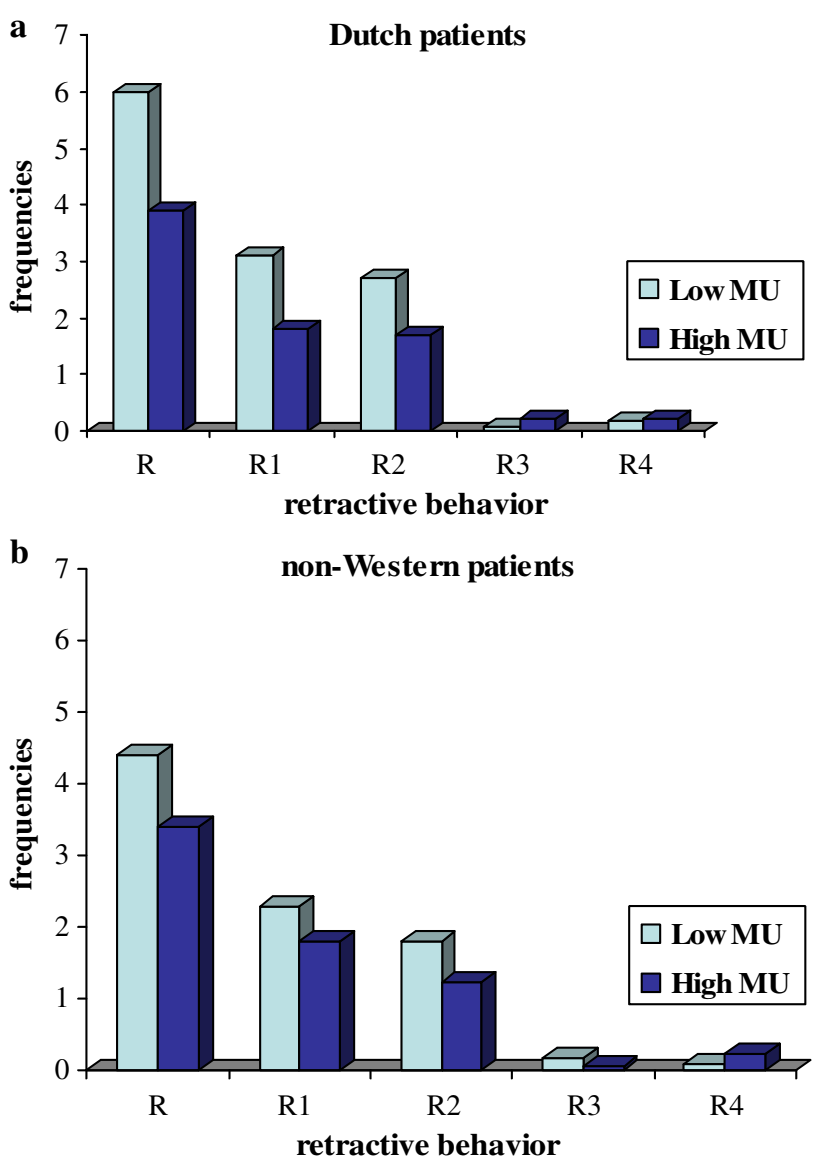

Fig. 1 (a) Frequencies of GPs' retractive behavior in consultations with (a) Dutch patients separate for low and high mutual understanding and (b) with non-Western patients separate for low and high mutual understanding

and another of "inattentive responding." As shown, the GP drives through the medical agenda by quickly instructing the patient about what to do and what to refrain from. The GP shifts from medication to food and drinks, often working on his PC at the same time, without asking the patient even once about what he feels about the recommended treatment. In other words, there is no sharing of decisions whatsoever. The GP does not check whether the patient understands what he is instructing him to do and does not react to the patient's concern about having to go to the toilet and his diarrhea.

In the second example the GP clearly tries to involve the patient in the decision-making process. The transcript concerns a 54-year-old female Turkish Muslim patient who has chronic back pain, with low mutual understanding between patient and GP. She has received treatment for her problems several times, but the pain never disappears. The transcript starts after the patient has explained the reason for visiting the GP. This part of the transcript has received four codes: two codes of "joint problem-solving", one of "storage failure" and one of "inattentive responding". The 
GP asks the patient several times what she thinks should be done about her problems. However, the patient reacts with great confusion to these questions, stuttering and repeatedly saying that she doesn't know what should be done. She is not willing and/or able to share in the decisionmaking process and answers yes to all that the GP suggests. Sentence 9 has been coded as "storage failure" because the GP asks the patient again about what she would like to do, while it is obvious that the patient has tried to make it clear that she doesn't know. Sentence 14 has been coded as "inattentive responding" because the GP does not react to the patient's last remark about her back pains.

\section{Discussion}

The results of this study show that GPs' interactional styles show less involvement when communicating with ethnic minority patients compared to Dutch patients. Doctors involve ethnic minority patients less in the decision-making process and check less often whether they understand each other than when interacting with Dutch patients. This lack of "joint problem-solving" clashes with the current norm of educating patients and sharing medical decisions with them. As every patient has the right to make informed decisions, doctors should at least verify whether the information they give is well understood by their patients.

It should be noted though that matters are not that clearcut when it comes to sharing medical decisions. There is a lot of evidence indicating that patients don't always prefer being involved in the decision-making process [26, 27], as our last fragment also illustrates. Previous research suggests that patients from non-Western backgrounds seem to have less need for information and decision-making than more Western-oriented patients [2, 28]. This raises the question of whether doctors are actually being less patientcentered when they do not involve their patients in the decision-making process, or whether they are just meeting the patient's wishes of not wanting to be involved in the same manner as Western patients. Future research is needed to shed more light on this issue.

Although we expected to find differences with regard to insensitivity to patients' level of understanding, no significant findings were found. Actually, doctors seldom made use of technical language and jargon. The fact that this was more common in the study by Roberts and Sarangi [21] may have to do with their use of medical students, who are less experienced in patient communication than the doctors in our study. Inattentiveness to patients' remarks and schema-driven progression occurred more, with the latter more frequently present in the Dutch group. Taken together though, differences between the groups were more manifest on stimulating behavior, indicating that intercultural consultations are more distinguishable from intracultural consultations by a lack of stimulating behavior than by GPs' use of retractive behavior.

Among the Dutch sample, GPs' use of retractive behavior occurred more frequently in consultations with low mutual understanding than in consultations with high mutual understanding. Ignoring patients' comments and driving through the medical agenda had a negative effect on the match between patients' and doctors' perceptions regarding the content of the consultation, such as cause of the health complaint and diagnosis. Surprisingly, in the case of ethnic minority patients low and high mutual understanding consultations could not be distinguished by GPs' retractive (or stimulating) behavior. A related study could not detect any differences in doctor-patient interactional styles between consultations high and consultations low in mutual understanding for ethnic minority patients either [10]. Apparently, the reasons for low mutual understanding between doctor and patient are different for Dutch patients than for ethnic minority patients. Limited research suggests that background variables, such as age and educational level, may have a more important influence on level of mutual understanding than doctor's communicative behavior [29].

In sum, the present study has pointed to some important differences in doctors' communicative behavior when interacting with Dutch patients and when interacting with ethnic minority patients. The amount of joint problemsolving is particularly less present in the ethnic minority patient group, which may pose problems in both a legal and a moral sense, as every patient has the right to make informed decisions.

There are some limitations to this study which should also be addressed. While the research sample was small, this study was not meant to make generalizations or representative statements regarding ethnic minority groups. Instead, the study intended to provide more understanding of variation in GPs' interactional styles in relation to patients' ethnic background. Selecting the lowest and highest quartiles of level of mutual understanding enabled detection of relevant differences, and the descriptive analysis revealed the pitfalls in medical communication with ethnic minority patients. Further, the use of the specific scoring technique developed by Roberts and Sarangi [11] limits the scope of the conclusions that can be drawn. This technique was particularly suited to investigate the concept of patient-centeredness and shared decision making in an interactional manner. As doctor-patient interaction is very complex, especially when it comes to intercultural differences, it would be worthwhile for future research to make use of more varied methods when studying differences in communication patterns as a function of patients' ethnic background. In order to make generalizations, future research should also use larger samples. These would allow investigating the predictive power of 
patients' ethnic background on doctor-patient communication in relation to other relevant background variables such as age, sex and socioeconomic status, as well as studying differences in communicative behavior within ethnic groups.

\section{Conclusion}

This study shows that GPs interact less stimulatingly with ethnic minority patients than with Dutch patients. Joint problem-solving is particularly less present. As every patient has a right to make informed decisions, GPs should check more often whether their patients have understood what has been said. However, as the extent to which patients actually want to be involved in the decisionmaking process is unknown, future research is needed to address this question. Factors that distinguish between intercultural consultations low and high in mutual understanding should also be identified, as good mutual understanding is positively linked to health-related outcomes like satisfaction and compliance [1]. Identifying such factors will enable GPs to improve their intercultural communicative skills, and to ensure that the quality of care for ethnic minority patients can be enhanced.

Open Access This article is distributed under the terms of the Creative Commons Attribution Noncommercial License which permits any noncommercial use, distribution, and reproduction in any medium, provided the original author(s) and source are credited.

\section{Appendix A}

Fragment 1: Example of a stimulating style

$1 \mathrm{p}$ : And then I fell like this, you can see how my cheek...

$2 \mathrm{~d}$ : Of your bike?

3 p: Yes. I fell and he said "didn't you see it", and I said "well, if I had seen it, I would not have continued driving."

$4 \mathrm{~d}$ : Exactly, because all these lights are flashing already there and..

5 p: yeah, yeah. But you see, my face hurts, it is all blue.

$6 \mathrm{~d}$ : Yes, I can see that.

7 p: But my back...just terrible.

$8 \mathrm{~d}$ : I will take a look at it in a minute, but I think that you have more things, haven't you?

Fragment 2: Example of a retractive style

$1 \mathrm{p}$ : I have read information about pills that can help you quit smoking.

2 a: That's for another consultation.

3 p: Yes.

4 a: Entirely different. That is unrelated to what you came here for.

$5 \mathrm{p}$ : Well, I wanted to have..

6 a: yes (his eyes are directed towards his computer)

$7 \mathrm{p}$ : some information about it.
Table a continued

8 a: Eh. (Picks up prescription note)... you should first do something about... you want to quit

9 Smoking? Fine. Then start with writing down the advantages of smoking and the disadvantages of smoking, Because these pills are only to support you.

10 p: Yes, well I.

11 a: No, you don't have to tell it me right now.

\section{Appendix B}

\section{Surinamese Hindu patient with stomachache}

$1 \mathrm{~d}$ : All right, sit down. (doctor and patient sit down, doctor works on $\mathrm{PC}$ ).

2 I will give you these other medicines. You have to take them twice a day. $\mathbf{R 2}$

3 p: Yes.

4 d: For 10 days. If it doesn't help, you have to come back.

5 p: Yes.

$6 \mathrm{~d}$ : You also have to eat healthy, lots of vegetables and fruit. Do you eat that?

7 p: Hm, yes moderately.

$8 \mathrm{~d}$ : Yeah. And furthermore....so, eat healthy.... and not too spicy or too sharp.

9 p: Yes.

$10 \mathrm{~d}$ : Also, not too many baked food. So, don't eat things like French fries.

$11 \mathrm{p}$ : Yes.

$12 \mathrm{~d}$ : Just plain rice and potatoes.

13 p: Yes.

14. d: Don't drink carbonated soft drinks too.

$15 \mathrm{p}: \mathrm{Hm}, \mathrm{hm}$.

$16 \mathrm{~d}$ : Do you drink that often?

17 p: Yes, mostly Coca Cola.

$18 \mathrm{~d}$ : Yeah, well, I should not drink that for a couple of weeks. The sugar it contains is not so

19 good for you, but in particular the carbon acid is not allowed.

20 p: Carbon acid.

$21 \mathrm{~d}$ : I think it is mainly your large intestines that trouble you. More so then your stomach. (Doctor starts working on PC).

$22 \mathrm{p}$ : The last couple of days I often have to go to the toilet in the morning.

$23 \mathrm{~d}$ : A lot (doctor continues working on PC).

$24 \mathrm{p}$ : Yes, it is always diarrhoea like and dark.

$25 \mathrm{~d}$ : I also want to give you this. And what I also want to give is syrup for your stomach. R1

Turkish Muslim patient with back problems

$1 \mathrm{~d}$ : What should we do? Because you already have had medicines, you have had physiotherapy. So, what should we do? S2

2 p: Ehm, yes, I don't know. Really, don't know..I d..d..d...d...d..don't know.(4 seconds silence). I cannot talk.. lots of problems. 
Table b continued

$3 \mathrm{~d}: \mathrm{Hmm}$

4 p: I, then I..i..i..i..i..i... stop.

5 d: Yes.

6 p: I know, I am a lot...I don't know. Wh..wh..wh... what did you ask me?

$7 \mathrm{~d}$ : Because you have problems for a long time now, I thought you want something special? R3

8 p: Yes. I don't know. Really, I don't know.

$9 \mathrm{~d}$ : Hmm.

10 [Patient talks on about her back aches. Doctor examines her. Patient's last remark concerns her pain]

$11 \mathrm{~d}$ : What do you think? Shall we try massage once again? R1

$12 \mathrm{p}$ : Yes.

13 d: Yes? S2

14 p: Yes.

15 d: Or medicines?

$16 \mathrm{p}$ : Yes.

$17 \mathrm{~d}$ : What do you think?

$18 \mathrm{p}$ : [Silent for about three seconds]. Massage.

\section{References}

1. Roter D, Hall JA. Doctors talking with patients/Patients talking with doctors. Westport: Auburn House; 1992.

2. Schouten BC, Meeuwesen L. Cultural differences in medical communication: a review of the literature. Pat Educ Couns. 2006;64:21-34

3. Cooper LA, Roter DL, Johnson RL, Ford DE, Steinwachs DM, Powe NR. Patient-centered communication, ratings of care, and concordance of patient and physician race. Ann Intern Med. 2003;139:907-15.

4. Hooper EM, Comstock LM, Goodwin JM, Goodwin JS. Patient characteristics that influence physician behavior. Med Care. 1982;20:630-8.

5. Meeuwesen L, Harmsen JA, Bernsen RM, Bruijnzeels MA. Do Dutch doctors communicate differently with immigrant patients than with Dutch patients? Soc Sci Med. 2006;63:2407-17.

6. Saha S, Komaromy M, Koepsell TD, Bindman AB. Patientphysician racial concordance and the perceived quality and use of health care. Arch Intern Med. 1999;159:997-1004.

7. Murray-García JL, Selby J, Schmittdiel J, Grumbach K, Quesenberry C. Racial and ethnic differences in a patient survey: Patients' values, ratings, and reports regarding physician primary care performance in a large health maintenance organization. Med Care. 2000;38:300-10.

8. Harmsen JAM, Meeuwesen L, van Wieringen J, Bernsen R, Bruijnzeels $M$. When cultures meet in general practice: intercultural differences between GPs and parents of child patients. Pat Educ Counsel. 2003;51:99-106.

9. Laveist TA, Nuru-Jeter A. Is doctor-patient race concordance associated with greater satisfaction with care? J Health Soc Behav. 2002; 4:296-306.
10. Meeuwesen L, Tromp F, Schouten BC, Harmsen H. Cultural differences in managing information during medical interaction: How does the physician get a clue? Pat Educ Counsel. 2007; 67:183-90.

11. Roberts C, Sarangi S. Mapping and assessing medical students' interactional involvement styles with patients. In: SpellmanMiller K, Thompson P, editors. Unity and diversity in language use: British studies in Applied Linguistics 17. London: Continuum; 2002.

12. Dupuis HM, Beaufort de, ID. Informed consent. In: Dupuis HM, Beaufort de ID editors. Handboek Gezondheidsethiek [Handbook Health Ethics]. Assen/Maastricht: van Gorcum; 1988.

13. Roter D. The enduring and evolving nature of the patient-physician relationship. Pat Educ Counsel. 2000;39:5-15.

14. Stewart M, Brown JB, Weston WW, McWinney IR, McWilliam CL, Freeman JR. Patient-centered medicine: Transforming the clinical method. London: Sage; 1995.

15. Haes $\mathrm{H}$, de Koedoot N. Patient centered decision-making in palliative cancer treatment: a world of paradoxes. Pat Educ Couns. 2003;50:43-9.

16. Wear S. Informed consent: patient autonomy and physician beneficence within clinical medicine. Dordrecht: Kluwer Academic Publishers; 1993.

17. Mead N, Bower P. Patient-centredness: a conceptual framework and review of the empirical literature. Soc Sci Med. 2000; 51:1087-110.

18. Gumperz J. Discourse strategies. Cambridge: Cambridge University Press; 1982.

19. Tannen D. New York Jewish conversational style. Int J Soc Language. 1981;30:133-49.

20. Goffmann E. Encounters: two studies in the sociology of interaction. Indianapolis, IN: Bobbs-Merrill; 1962.

21. Roberts C, Wass V, Jones R, Sarangi S, Gillett A. A discourse analysis study of "good", "poor" communication in an OSCE: a proposed new framework for teaching students. Med Educ. 2003;37:192-201.

22. Harmsen JAM. When cultures meet in medical practice, Ph.D. thesis. Rotterdam: Erasmus University; 2003.

23. Have Pt. Doing conversation analysis: a practical guide. London: Sage; 1999.

24. ISEO. Beter meten [Measuring better]. Rotterdam: Instituut voor Sociologisch Economisch Onderzoek; 1987.

25. Harmsen JA, Bernsen RM, Meeuwesen L, Pinto D, Bruijnzeels MA. Assessment of mutual understanding of physician patient encounters: development and validation of a Mutual Understanding Scale (MUS) in a multicultural general practice setting. Pat Educ Couns. 2005;59(2):171-81.

26. Beisecker AE, Beisecker TD. Patient information-seeking behaviors when communicating with doctors. Med Care. 1990;28:19-28.

27. Braman AC, Gomez RG. Patient personality predicts preference for relationships with doctors. Pers Indiv Differ. 2004;37:815-26.

28. Blackhall LJ, Murphy ST, Frank G, Michel V, Azen S. Ethnicity and attitudes toward patient autonomy. J Am Med Assoc. 1995;274:820-5.

29. Schouten BC, Meeuwesen L, Tromp F, Harmsen HA. Cultural diversity in patient participation: the influence of patients' characteristics and doctors' communicative behaviour. Pat Educ Counsel. 2007;67:214-23. 